\title{
In This Issue: Teachable Moments for Patients, Practices, and Systems
}

\author{
Kurt C. Stange, $M D, P b D$, Editor \\ Ann Fam Med 2018;16:286-287. https://doi.org/10.1370/afm.2277
}

$\mathrm{T}$ The ability to identify and act on a teachable moment ${ }^{1}$ is one of the hidden reasons why systems based on primary care have better outcomes. Primary care increasingly routinizes and involves teams in preventive and chronic disease care. This is a good thing. But it masks the subtle value of a careful clinician or staff member recognizing when something has shifted in a patient's life that makes them amenable to changing a long-held belief or habit—an aunt's amputation makes a diabetic get serious about diet and activity, the divorce of a friend shakes a partner's complacency and foments re-investment in a relationship, a child's third episode of otitis media makes an incorrigible grandmother consider quitting smoking when the doctor mentions that having a smoker in the house doubles the risk of a child having an ear infection.

Health care professionals, and (I hopefully assert) even the health care system, is not immune to teachable moments. ${ }^{*}$ I like to call them malleable moments, ${ }^{3}$ not just because I am a sucker for alliteration, but to emphasize that in every moment we all have the possibility of positive change, ${ }^{4}$ if only we can focus our attention on being the change we wish to see. ${ }^{5}$

This issue contains new knowledge about teachable moments, and the potential to create malleable moments for positively changing patients, practices, and systems.

Schmittdiel et al examine the influence of a new diagnosis of diabetes on the health behaviors of patients' partners, and find small but significant (from both statistical and public health points of view) changes in a host of health behavior and preventive activities. ${ }^{6}$

A cluster-randomized clinical trial of an interactive booklet on childhood fever and out-of-hours primary care is found to apparently induce teachable moments for both families and the physicians who use it. Parents

\footnotetext{
* Teachable moments happen when: "(1) the presence of a concern that is salient to the patient that is either obviously relevant to an unhealthy behavior, or through conversation comes to be seen as relevant; (2) a link that is made between the patient's salient concern and a health behavior that attempts to motivate the patient toward change; and (3) a patient response indicating a willingness to discuss and commit to behavior change." 2
}

show a reduced intention to re-consult for similar illnesses. The reduction in the primary outcome of antibiotic prescription for patients of physicians exposed to the booklet did not reach statistical significance, but pre-specified analysis of those using the booklet found a reduction in antibiotic prescriptions, and a reduction in overall medication prescriptions. ${ }^{7}$

Delacour et al find a strong association between alcohol consumption and leg cramps in general practice patients aged over 60 years. ${ }^{8}$ They don't find a dose-response effect, but I wonder if the immediacy of leg cramps could be a motivator for some patients for whom the long-term effects of alcohol overuse are not compelling.

In a prospective study, Valderas et al discover individual patient characteristics that predict new cases of multimorbidity. ${ }^{9}$ This finding could be used to foster teachable moments among patients with a single chronic illness who might be motivated to make changes to avoid an additional chronic condition.

A referral from a primary care to a behavioral health clinician frequently comes at a teachable moment. Pace et al examine whether a "warm handoff" introducing patients to an integrated behavioral health clinician improves attendance at the follow up appointment. It doesn't. But having an intake appointment within 30 days of referral does. ${ }^{10}$

A fascinating article by Donner-Banzhoff examines the diagnostic process in general practice. He proposes that simple theories don't fit the large primary care problem space. But patients and clinicians collaborate in ways he calls "inductive foraging" that integrate both diagnosis and patient-centered consulting. ${ }^{11}$

This issue also contains some teachable moments for clinicians, practices, and health care systems.

In a study of 43,382 US medical school graduates, Talamantes and colleagues discover that attendance at a community college is associated with subsequent training in a family medicine residency. ${ }^{12}$ Noting that more than one-half of medical students come from families in the top $20 \%$ of income, and less than $5 \%$ of medical students have parents in the bottom $20 \%$ of 
income, an editorial by Kost makes a strong case that admitting students from community colleges could help medical schools to do a better job of meeting their societal responsibility by training a physician workforce positioned to care for the disadvantaged. ${ }^{13}$

Patients increasingly are being provided with access to their electronic medical records, but there have been some concerns about whether this is a good idea for people with mental health issues. A research brief by Elmore and colleagues allays this concern, finding that patients viewing at least one of their clinic notes during a one-year period have similar perceptions of online access whether or not they have a mental health diagnosis. ${ }^{14}$

An evaluation of prominent mental health apps by Parker et al finds that mental health often is framed in ways that may promote medicalization of normal mental states and that implies individual responsibility for mental well-being. ${ }^{15}$

A study by Burt and colleagues examines physicians' communication skills from the perspectives of patients, trained clinical raters, and physicians themselves. ${ }^{16}$ The lack of correlation between physician self-ratings and the other ratings indicates that we physicians have limited awareness of how our communication skills are perceived by others.

A brief qualitative study by Havele et al finds that a compelling belief in the ability of blood glucose selfmonitoring to promote lifestyle changes in patients with type 2 diabetes explains why physicians remain proponents of this practice despite evidence that self-monitoring increases costs without improving outcomes. ${ }^{17}$

A microsimulation model by Basu and colleagues estimates the conditions under which it would be financially viable to have a staff member enter patient history, place orders, and guide patients-in both feefor-service and capitated payment. ${ }^{18}$

Three essays provide their own kinds of teachable moments. In light of the growing phenomenon of parttime practice, Bodenheimer sees ways that clinicians and practices can make a number of adjustments to foster continuity and relationships. ${ }^{19}$ Goodfellow suggests that care of patients suffering from the effects of interpersonal violence is improved simply by believing our patients' pain. ${ }^{20}$ Kannai provides insights through her experience and reflection on how clinicians can overcome blind spots in grasping patients' complex inner struggles. ${ }^{21}$

The Annals feature on Innovations in Primary Care in this issue shares the experience of a family physician who has found ways to integrate rapid acupuncture into daily family practice. ${ }^{22}$

We welcome you to join the online discussion for each of these and previously published articles at http://www.AnnFamMed.org.
Acknowledgments: Thanks to my colleague, Sue Flocke, who has been studying teachable moments for more than two decades. She notes that these moments are about the potential to see something in a different light. In clinical care, realizing the resulting potential for change hinges on clinicians' hearing patients' salient concerns, and if the time is right, helping patients to consider change. Teachable moments are co-created between patient and clinician. ${ }^{1}$

\section{References}

1. Lawson PJ, Flocke SA. Teachable moments for health behavior change: a concept analysis. Patient Educ Couns. 2009;76(1):25-30.

2. Cohen DJ, Clark EC, Lawson PJ, Casucci BA, Flocke SA. Identifying teachable moments for health behavior counseling in primary care. Patient Educ Couns. 2011;85(2):e8-15.

3. Ruhe MC, Weyer SM, Zronek S, Wilkinson A, Wilkinson PS, Stange KC. Facilitating practice change: lessons from the STEP-UP clinical trial. Preventive Medicine. 2005;40(6):729-734.

4. Easwaran E. Conquest of Mind. Tomales, California: Nilgiri Press; 1988.

5. Easwaran E. Gandhi the Man. 3rd ed. Tomales, California: Nilgiri Press; 1997.

6. Schmittdiel JA, Cunningham SA, Adams SR, Nielson J, Ali MK. Influence of a new diabetes diagnosis on the health behaviors of a patient's partner. Ann Fam Med. 2018;16(4):290-295.

7. de Bont EGPM, Dinant G, Elshout G, et al. Booklet for childhood fever in out-of-hours primary care: a cluster-randomized controlled trial. Ann Fam Med. 2018;16(4):314-321.

8. Delacour C, Chambe J, Lefebvre F, et al. Association between alcohol consumption and nocturnal leg cramps in patients over 60 years old: a case-control study. Ann Fam Med. 2018;16(4):296-301.

9. Mounce LTA, Campbell JL, Henley WE, Tejerina Arreal MC, Porter I, Valderas JM. Predicting incident multimorbidity. Ann Fam Med. 2018;16(4):322-329.

10. Pace CA, Gergen-Barnett K, Veidis A, et al. Warm handoffs and Attendance at Initial Integrated Behavioral Health Appointments. Ann Fam Med. 2018;16:346-348.

11. Donner-Banzhoff N. Solving the diagnostic challenge: a patientcentered approach. Ann Fam Med. 2018;16(4):353-358.

12. Talamantes $E$, Jerant $A$, Henderson $M C$, et al. Community college pathways to medical school and family medicine residency training. Ann Fam Med. 2018;16(4):302-307.

13. Kost A. Building a pipeline to equity. Ann Fam Med. 2018;16(4): 288-289.

14. Klein JW, Peacock S, Tsui JI, O'Neill SF, DesRoches CM, Elmore JG. Perceptions of primary care notes by patients with mental health diagnoses. Ann Fam Med. 2018;16(4):343-345.

15. Parker L, Bero L, Gillies D, et al. Mental health messages in prominent mental health apps. Ann Fam Med. 2018;16(4):338-342.

16. Burt J, Abel G, Elliott MN, et al. The evaluation of physicians' communication skills from multiple perspectives. Ann Fam Med. 2018;16(4):330-337.

17. Havele SA, Pfoh ER, Yan C, Misra-Hebert AD, Le P, Rothberg MB. Physicians' views of self-monitoring of blood glucose in patients with type 2 diabetes not on insulin. Ann Fam Med. 2018;16(4):349-352.

18. Basu S, Phillips RS, Bitton A, Song Z, Landon BE. Finance and time use implications of team documentation for primary care: a microsimulation. Ann Fam Med. 2018;16(4):308-313.

19. Bodenheimer T, Haq C, Lehmann W. Continuity and access in the era of part-time practice. Ann Fam Med. 2018;16(4):359-360.

20. Goodfellow A, Bone C, Gelberg L. They didn't believe her pain: my education in interpersonal violence. Ann Fam Med. 2018;16(4):361-363.

21. Kannai R, Alon A. On blindness and blind spots. Ann Fam Med. 2018;16(4):364-366.

22. Koda EK. Fully integrating medical acupuncture into family medicine. Ann Fam Med. 2018;16(4):367-367. 